\title{
Online Tools for Improving Student Feedback Reading Rate
}

\author{
Shawn O'Rourke, Tim Sawicki \\ Canisius College, Buffalo, NY, USA
}

\begin{abstract}
Online programs and courses continue to grow at a rapid rate and it is imperative that studies continue to review all aspects of best practices for online teaching. More than 22 million students [1] are projected to take some or all of their classes online in the next five years. Personalized communication is critical to the engagement and retention of online students [2]. Quality written feedback is one of the factors that make up a good online class. Faculty feedback collected from the Canisius College's online Master of Sport Administration were studied to highlight the importance of effective communication in online education. Research by Sawicki and O'Rourke [16] showed that students read their online written feedback approximately $40 \%$ of the time depending on the feedback reading prompts from the instructor and the value of the assignment. This result led the researchers to study four courses with a range of twenty to twenty-four students in each of the classes from the Master of Science Sport Administration program. In each course grades were withheld on student assignments. Grades were usually posted to the gradebook but in this study, none were provided in the gradebook. By doing this the students were forced to go into their assignment drop box to read their online written feedback and read their numerical grade which was included with the qualitative written feedback. The numerical grade with their written feedback was provided in the 'Dropbox' and was not posted to the gradebook as is typical for online courses. On major assignments, (those worth $15 \%$ to $20 \%$ of final grade) $100 \%$ feedback reading rate was found, with minor assignments (10\% or less of final grade) there was an approximately $76 \%$ reading rate feedback. This drastically improved on the approximately $40 \%$ online written feedback reading rate shown in the Sawicki and O'Rourke [16] study.
\end{abstract}

\section{Introduction}

The three types of interaction while taking an online course are: student to student, student to instructor and the content of the course interactions (instructor to student). Student to student interaction encourages students to engage and learn from each other. Learning from other individuals' viewpoints is one of the contributing factors to open-minded learning in an intercollegiate environment. An example would be students participating in a discussion forum. These discussion forums are often the primary means of interaction during an online course. They allow students to take part in asynchronous activities, reflect on the content and ask any questions they might have. The instructor and other students have an opportunity to respond to the Discussion posts. This may happen many times for one Discussion post.

Student to instructor interaction occurs when students ask the instructor a question and he/she requires a response in a timely manner. Instructor to student interaction provides students one-on-one feedback. An example would be providing online written feedback for an assignment. Instructor to student interaction allows students to learn and reflect on what they have learned.

Our research work focuses on instructor to student interaction where it pertains to online written feedback that the instructor provides to the student and whether or not the student reads and thus learns from this feedback. It has been shown that Sport Administration courses need to ensure meaningful student learning and have effective teaching for positive student experiences [18]. Providing important written online feedback is essential for Sports Administration courses. Teaching online requires instructors to think differently because the exchange between students is the interactive 
dissemination of information. To be successful online, students must have self-disciplined and motivated because the schedule to complete assignments is very flexible and open-ended.

\section{Literature Review}

The rapid growth of online education has been led by demographics or economic considerations more than student's satisfaction, learning outcomes [8], [2], or empirical evidence of effectiveness [9]. As online education has been growing exponentially through the last few years, some researchers consider that empirical evidence is still lacking to support effectiveness and benefits for the student [9]. However, it is important to mention that Petrides [13] and Vonderwell [23] found that students engaged in an asynchronous online learning reported to be more encouraged by reflective thinking and introspection that online courses provide. MacNeely [24] confirms that in order to be successful in online education, one needs to make sure technology isn't only the 'new cool thing': it is a learning tool!

On the other side of the spectrum, literature has identified development of interpersonal contacts as one of the weaknesses on online education. Thus, Vonderwell [23] and Song, Singleton, Hill and Koh [17] reported that student's biggest disappointment with online learning was related to the lack of communication and community. However, Rovai [14] demonstrates that this feeling of community improves when professor and students provide each other feedback in timely manner and by giving the opportunity to participate in online exchanges. Therefore, feedback is an integral part of online teaching best practices.

The ease of online courses ability to serve many students that they would normally be unable to reach because of geographical location and tight schedules is a significant factor in selecting online programs [20]. Many challenges can obstruct the way to online education excellence: financial cost, technological obstacles [19], faculty training [10] and the need to interact in a timely manner [14], Muirhead and Betz [11], Song, Singleton, Hill and Koh [17, among others. Also, one has to bring relevant knowledge, regardless of the age and technological ability of the student [6], [5]. For our purposes, online learning is conceptualized in a way where students are taught by the faculty member via the computer (over internet) in such a way that the student is not required to be physically present on campus or in the classroom at any time.
There are three types of interaction while taking an online course. There are: student to student, student to instructor and the content of the course interactions (instructor to student). Student to student interaction encourages students to engage and learn from each other. Learning from other individuals' viewpoints is one of the contributing factors to open-minded learning in an intercollegiate environment. An example would be students participating in a discussion forum. These discussion forums are often the primary means of interaction during an online course. They allow students to take part in asynchronous activities, reflect on the content and ask any questions they might have. The instructor and other students have an opportunity to respond to the Discussion posts. This may happen many times for one Discussion post.

Student to instructor interaction occurs when students ask the instructor a question and he/she requires a response in a timely manner. Instructor to student interaction provides students one-on-one feedback. An example would be providing online written feedback for an assignment. Instructor to student interaction allows students to learn and reflect on what they have learned.

This study will focus on instructor to student interaction where it pertains to online written feedback that the instructor provides to the student and whether or not the student reads and thus learns from this feedback. It has been shown that Sport Administration courses need to ensure meaningful student learning and have effective teaching for positive student experiences [18]. Providing important written online feedback is essential for Sports Administration courses. Teaching online requires instructors to think differently because the exchange between students is the interactive dissemination of information. To be successful online, students must have self-disciplined and motivated because the schedule to complete assignments is very flexible and open-ended.

Coll, Rochera and de Gispert [4] proposed an analytic framework for how and when feedback is best given for knowledge building in collaborative online settings. The authors stated more research is needed regarding feedback patterns in varied higher education programs in different countries.

Walvoord and Anderson [21] further noted that ongoing formative feedback on student work is much more valuable than waiting to provide extensive feedback on the final assignment. By providing feedback throughout the course or on pieces of large assignments as they are completed, the instructor acts 
as a coach, moving students toward the goal of achieving higher-order thinking skills. Having clear expectations and grading criteria creates consistency in grading and helps engage learners in their own learning process, as they know what they are aiming for and can assess their own progress along the way.

McVay Lynch [7] noted that good assessment uses multiple measures of student performance. This leads to the more likelihood that a true measurement of student competency and performance will result. The use of multiple measures of assessment is simply good pedagogy. Providing regular student written feedback will lead to optimal student learning.

The quality and quantity of feedback needs to be relevant, specific and understandable and the timing of feedback is crucial. For most students, the time frame within which it is possible to learn from, and apply, feedback from one piece of work to another is narrow, particularly within a single module. Changes need to occur to move away from the frustrating cycle of large amounts of unread feedback [12]. This leads to the question if students often miss reading their online feedback, are there ways to improve the likelihood that students will read their online feedback. The current research addresses this question.

Research by Sawicki and O'Rourke [16] showed that students read their online written feedback approximately $40 \%$ of the time depending on the feedback reading prompts from the instructor and the value of the assignment. The study also showed that students read their major assignments at a slightly higher rate than minor assignments and they read feedback earlier in the course at more frequent rate than later assignments. This led to the current research which is studying ways to improve the student reading rate of their online written feedback while taking online courses. The research was conducted using four courses with a range of twenty to twenty-four students in each of the classes from the Master of Science Sport Administration program at Canisius College.

\section{Method}

The current research looked at two ways to increase students reading their online written feedback. The study detailed feedback reading patterns using four classes of graduate courses with a total number of 88 students. The instructor in the four classes provided feedback and grades all in the same location, which is called the 'Dropbox.' These courses were fully online and taught asynchronously (each student can log in at any given time to discover the class content, post reactions, etc.) during the week. Each course used various tools of online communication including: video, slides, podcast and written document), announcements, course documents and other additional resources, student pages, email, discussion boards, assignment Drop Boxes, and group discussion areas. The learning management delivery system used was Desire 2 Learn (D2L).

The 'Dropbox' is where students attached their assignments. The 'Dropbox,' allows documentation when students work was submitted and also time and day when instructor feedback was read by the student.

During the course, students were asked via the announcements board to read their feedback for each module assignments. Assignments were valued from $10 \%$ of their final grade to as much as $25 \%$ of their final grade across course modules. There were six assignments in total per course. Two assignments at $10 \%$, one at $15 \%$, two at $20 \%$ and one assignment worth $25 \%$. Feedback data was collected pertaining to whether the students read their written online feedback and whether they read the feedback early in the course (two weeks to four weeks), middle of course, (five to seven weeks) or at the end of the course (eight to ten weeks). The value or percentage of the assignment were also considered.

No numerical grades were recorded using the online gradebook. This was designed so students would have to go to their 'Dropbox' and read their written feedback and view a numeric grade. The instructor gave written feedback and a numeric grade within 48 hours of the assignment due date. This was done so students would know when they could go to their 'Dropbox' to read their written feedback and check their numeric grade.

It is hypothesized that requiring students to go to the 'Dropbox' to receive their written student feedback and receive their grade would result in $100 \%$ feedback reading rate. Students would not know how they are performing in the course without going to the 'Dropbox.'

\section{Results}

The research looked at improving the rate that students read their online feedback from an earlier study by Sawicki and O'Rourke [15] which showed approximately $34 \%$ of students read their online 
Table 1. Percentage of Written Feedback Reading Rates for Students Taking Online Courses In the Master of Science-Sport Administration Online Graduate Program

\begin{tabular}{|l|l|l|l|l|l|l|}
\hline $\begin{array}{l}\# \quad \text { of } \\
\text { students }\end{array}$ & $\begin{array}{l}\text { Mod.1 } \\
(10 \%-F G)\end{array}$ & $\begin{array}{l}\text { Mod.2 } \\
(15 \%-F G)\end{array}$ & $\begin{array}{l}\text { Mod. 3 } \\
(20 \%-F G)\end{array}$ & $\begin{array}{l}\text { Mod. 4 } \\
(10 \%-F G)\end{array}$ & $\begin{array}{l}\text { Mod. 5 } \\
(20 \%-F G)\end{array}$ & $\begin{array}{l}\text { Final Exam/Project } \\
(25 \%-F G)\end{array}$ \\
\hline $\begin{array}{l}\text { Total/20 } \\
\text { Course 1 }\end{array}$ & 16 & 15 & 16 & 12 & 20 & 20 \\
\hline$\%$ FB Read & $80 \%$ & $75 \%$ & $100 \%$ & $60 \%$ & $100 \%$ & $100 \%$ \\
\hline $\begin{array}{l}\text { Total/22 } \\
\text { Course 2 }\end{array}$ & 16 & 17 & 22 & 20 & 22 & 22 \\
\hline$\%$ FB Read & $72 \%$ & $77 \%$ & $100 \%$ & $90 \%$ & $100 \%$ & $100 \%$ \\
\hline $\begin{array}{l}\text { Total/22 } \\
\text { Course 3 }\end{array}$ & 15 & 17 & 22 & 17 & 22 & 22 \\
\hline$\%$ FB Read & $68 \%$ & $77 \%$ & $100 \%$ & $77 \%$ & $100 \%$ & $100 \%$ \\
\hline $\begin{array}{l}\text { Total/24 } \\
\% \text { FB Read }\end{array}$ & 20 & 18 & 24 & 18 & 24 & 24 \\
\hline$\%$ FB Read & $83 \%$ & $75 \%$ & $100 \%$ & $75 \%$ & $100 \%$ & $100 \%$ \\
\hline $\begin{array}{l}\text { Total \% FB } \\
\text { Read }\end{array}$ & $75.75 \%$ & $76 \%$ & $100 \%$ & $75.50 \%$ & $100 \%$ & $100 \%$ \\
\hline
\end{tabular}

written feedback and Sawicki and O'Rourke [16] which used feedback prompts and showed approximately $40 \%$ of the students read their online written feedback. The current study found that requiring students to read and reflect on their online written feedback for a grade resulted in students reading their feedback $100 \%$ of the time when the assignment was worth $20 \%$ or greater of the student's overall grade. Conversely, when the assignment was worth $15 \%$ or less, the students read $75.64 \%$ of the instructor's feedback (see Table 1 ).

It is shown in this study that there is a high compliance among students to read their online written feedback when students' assignments are worth $20 \%$ or $25 \%$. There is less compliance towards reading online feedback when assignments are lesser valued at $10 \%$ or $15 \%$. Providing the numeric grade with the written feedback in the 'Dropbox' promoted students reading their written online feedback. Across all assignment a percentage range of $75 \%$ to $100 \%$ rate of reading online written feedback occurred. The $75.6 \%$ feedback reading rate for the $10 \%$ assignments and $76 \%$ for $15 \%$ assignments is somewhat perplexing. It can be speculated that some students do not know how to look at their online written feedback or know where to look for it or they do not see it as useful. This supports the findings of Careless [3] who stated that students do not always find their online feedback useful. It may also be that since the $75.6 \%$ feedback reading rate was on minor assignments $(10 \%$ of the final grade) and $76 \%$ (on the $15 \%$ assignment), students may feel it is not worth the time to read their online feedback for lesser assignments. There was $100 \%$ feedback reading rate on assignments worth $20 \%$ or $25 \%$. Interestingly to note, when data was reviewed to determine if it was the same students not reading their feedback, it was shown that there was no consistency with which students were not reading their feedback. The results show it was not the same students not reading their online written feedback, it was spread out through the whole class of students.

In van der Pol, van der Berg, Admiraal and Simons [22] it was shown that there was a high correlation between how useful students felt the feedback was and how often they viewed their online feedback. The concept of how useful the students find the online written feedback may be important in the current study and might have implications for the current results. Future studies directed at finding out how useful the students perceive their online written feedback should be investigated. The approximately $76 \%$ reading online feedback reading rate for minor assignments indicates that most students find online written feedback valuable but they feel they do not need to read it on every assignment (especially on lower valued assignments).

\section{Conclusion}

The current study vastly improved on the approximately $36 \%$ and $40 \%$ feedback reading rate respectively in the two previous studies [15] and [16]. Online instructors should withhold the students' numeric grade on assignments from the gradebook. Requiring students to read their online written feedback before viewing their numeric grades is the best practice for getting students to read their online written feedback. Summarizing two previous studies and the current research. Instructors should post an announcement for students to read their online written feedback [15]; instructor's should use prompts (i.e., require students to read their written feedback for a numeric grade) [16]. The current 
study showed instructors should withhold numeric grades from the gradebook so students have to go to the 'Dropbox' to read their online written feedback. Instructors undertaking these three aspects will lead to the majority of students reading their online written feedback.

\section{References}

[1] Academic impressions.com, February (2011). https://w ww.academicimpressions.com/ (Access Date: April 21, 2018).

[2] Betts, K., (2009). Lost in Translation: Importance of effective communication in online education. Online Journal of Distance Learning Administration, Volume XII, Number II.

[3] Careless, D., (2006). Differing Perceptions in the Feedback Process. Studies in Higher Education, 31(2), 219-233.

[4] Coll, C., Rochera, M.J, and de Gispert, I., (2014). Supporting online collaborative learning in small groups: teacher feedback on learning content, academic task and social participation. Computers and Education, 75, 53-64.

[5] Hartman, J., Moskal, P., and Dziuban, C. (2005). Preparing the academy of today for learner of tomorrow, in Oblinger, D.G. and Oblinger, J.L. (eds). Educating the net generation, Washington: Educause.

[6] MacNeely, B., (2005). Using technology as a learning tool, not just the new cool thing, in Oblinger, D.G. and Oblinger, J.L. (eds). Educating the net generation, Washington: Educause.

[7] McVay Lynch, M., (2002). The Online Educator: A Guide to Creating the Virtual Classroom. London: RoutledgeFalmer.

[8] McKenzie, B. K., Ozkan, B.C., and Layton, K., (2006). Tips for administrators in promoting distance programs using peer mentoring, Online Journal of Distance Learning Administration, 9, 2 .

[9] Moore, M.G. and Anderson, E.G., (2003). Handbook of Distance Education (pp. 245- 260). Mahwah, N, Lawrence Erlbaum Associates.

[10] Moore, A., Moore, J. and Fowler, S., (2005) Faculty development for the net generation, in Oblinger, D.G. and Oblinger, J.L. (eds). Educating the net generation, Washington: Educause.

[11] Muirhead, B. and Betz, M., (2002). Faculty training at an online university, United States Distance Learning Association Journal, 16(1).

[12] Murphy, C., (2010). Student perceptions of feedback: seeking a coherent flow. Practitioner Research in Higher Education, 4 (1), 41-51.
[13] Petrides, L.A., (2002). Web-based technologies for distributed (or distance) learning: Creating learningcentered educational experiences in the higher education classroom, International Journal of Instructional Media, 29(1), 69-77.

[14] Rovai, A.P., (200I). Building and sustaining community in asynchronous learning networks. The Internet and Higher Education, 3, 285-297.

[15] Sawicki, T. M. and O'Rourke, S., (2016). Use of Student Feedback for Online Learning. The International Journal for Digital Society (IJDS), Vol. 7 (2): 1152 - 1156.

[16] Sawicki, T. M. and O'Rourke, S. (2017). Use of Student Feedback for Online Learning. International Journal for Cross-Disciplinary Subjects in Education (IJCDSE), 8 (4): 3225 - 3229.

[17] Song, L., Singleton, E., Hill, J., and Koh, M., (2004). Improving online learning: Student perceptions of useful and challenging characteristics, The Internet and Higher Education, 7 (1), 59-70.

[18] Stier, W., and Schneider, R., (2009). Sport Management Taught On-Line: A Discussion, 5 (1), 55-68.

[19] Wager, J., (2005). Support services for the net generation, in Oblinger, D.G. and Oblinger, J.L., (eds). Education the net genera/ion, Washington: Educause.

[20] Weil, V., (2005). Standards for Evaluating Proposals to Develop Ethics Curricula, 11, 501- 507.

[21] Walvoord, B.E., and Anderson, V.J. (1998). Effective Grading: A Tool for Learning and Assessment. San Francisco: Jossey-Bass.

[22] van der Pol, J., van den Berg, B. A. M., Admiraal, W. F., and Simons, P. R. J., (2008). The nature, reception, and use of online peer feedback in higher education. Computers and Education, 51, 1804-1817.

[23] Vonderwell, S., (2003). An examination of asynchronous communication experiences and perspectives of students in an online course: A case study. Internet and Higher Education, 6, 77-90.

[24] MacNeely, B. (2005). Using technology as a learning tool, not just the new cool thing, in Oblinger, D. G. \& Oblinger, J. L. (eds). Educating the net generation, Washington: Educause. 